\title{
Contemporary challenges for project managers in Serbia
}

\author{
Katarina Pavlovic \\ Project Management Department \\ Faculty of Project and Innovation \\ Management \\ Belgrade, Serbia \\ katarina.pavlovic@pmc.edu.rs \\ Ivana Beric \\ Project Management Department \\ Faculty of Project and Innovation \\ Management \\ Belgrade, Serbia \\ ivana.beric@pmc.edu.rs
}

\author{
Vesna Sobajic \\ Project Management Department \\ Faculty of Project and Innovation \\ Management \\ Belgrade, Serbia \\ vesna.sobajic@pmc.edu.rs \\ Ljiljana Berezljev \\ Project Management Department \\ Faculty of Project and Innovation \\ Management \\ Belgrade, Serbia \\ 1jljana.berezljev@pmc.edu.rs
}

\author{
Mila Milenkovic \\ Digital Innovations and Applications \\ Department \\ Telekom Serbia \\ Belgrade, Serbia \\ mila@telekom.rs
}

\begin{abstract}
Project management profession encounters numerous challenges in today's global environment. It is a known fact for every project management professional that most common challenges are the completion of project on time, scope changes, goals, unplanned risks, engagement on several different projects, lack of competencies, lack of top management and stakeholder engagement, economic instability, legal barriers and many others. Through literature search, it was observed that there are no data related to challenges project managers face in Serbia, and for this reason, the aim of this paper is to provide this information, based on a study conducted. Challenges presented in the survey are most widely and statistically recognized ones as globally present, and the idea was to show how these challenges fit into contemporary project management practice in Serbia and to show the difference between small and large companies. The research part of the paper was based on a survey, presented to project managers in project management practising organizations in Serbia, large majority of which being from a service sector. Through this survey four hypotheses were tested. Methods of descriptive and analytical statistics were used for evaluation of the survey, and all four hypotheses were confirmed. Major challenges for project managers in Serbia were identified, and it was shown that the size of a company does have an impact on dealing with challenges. Based on the data provided decision-makers in organizations will get a clearer understanding of real challenges in project management in Serbia, which should allow for better decisions.
\end{abstract}

Keywords - project management challenges, local environment, project context

\section{INTRODUCTION}

In the past decades, organizations have been continually searching for project management improving methods, but are still struggling to achieve project goals and get desirable business results through projects [1]. It is requisite for every organization to implement the best practices and all the resources to successfully complete the project [2]. This seems to be easier to attain in developed countries than in countries with emerging economies. Applying best practices in project management can help Serbia improve its economic position and recover from the crisis of 2008, which significantly affected Serbia, and can help it find its place in world economy.

The situation regarding project management seems to be very similar globally, considering turbulent and dynamic environment [3], as well as globalization which brought a new dimension into project management in terms of geographical dislocation, cultural diversity and leadership styles.

In Serbia, the concept of project management was brought in the 1960s, during the second period of modern project management [4] and since then, there have been numerous projects covering improvements in infrastructure, education, private businesses and nongovernment organizations [5].

Serbia is in the process of transforming its economy from a planned economy into a market economy. In 2015 , the nominal GDP was about $\$ 5,900$ per capita, which is half of its neighbour Croatia [6]. Main sectors of the economy are services that account for $50 \%$ of GDP, followed by industry with $40 \%$ and agriculture with about $10 \%$.

Serbia has been trying to achieve a higher level of development [7]. Developed countries are mature and old economies, and most changes primarily originate from them. Such countries have stable growth and constant development, but they also suffer certain imbalances and crises. Developing countries try to respond to changes, and by using certain reforms they try to adjust their economies to the demands of the global market and integrations [8]. Among developing countries, there is a group of emerging economies.

Project management has been linked to development processes in every country, projects being considered a major building blocks [9]. What most countries have in common today, for effective project 
management is dealing with uncertainty, complexity, adaptability and a broad spectrum of challenges. Literature review shows a wide range of challenges in project management, which are not directly linked to specific demographic data. These challenges include unrealistic deadlines, poorly defined goals, changes in project scope, geographical dislocation of team members, handling of unplanned risks, simultaneous engagement of team members on different projects, lack of competencies, legal system and regulations, political and economic situation. This paper shows the study conducted in Serbia in order to examine these challenges from the perspective of Serbian project managers, to show the differences between companies surveyed as well as to open discussions for future research.

\section{RESEARCH BACKGROUND AND HYPOTHESIS}

Literature review shows that the biggest challenges in project management are poorly defined goals, changes in scope and unrealistic deadlines.

The first major challenge that project managers and team members face is not knowing what exactly to expect from the project. If the goals and objectives are not clearly defined, the project is most likely to fail.

The second challenge is scope creep, an uncontrolled change, which needs to be avoided. Scope changes affect the cost, the scheduling, and the duration of projects, both directly and indirectly. Project managers should analyze each request and then communicate the impact of each change and the alternatives if any exist. Change needs to be embraced, but stakeholders have to understand how the change affects the schedule, cost, scope, and quality of the project [10].

The third reason why most projects fail or what most project managers find difficult is unrealistic expectations, in terms of timeframe, that stakeholders have from them. Most project timelines at some point slip due to the unrealistic "initial deadlines" $[11,12]$. This is one of the big issues in today's environment, which is so turbulent, demanding and competitive that it drives companies to set deadlines unrealistic, trying to keep up with the competition. Organizations can expect value from their investment in projects only if there is a link between the outputs obtained and the requirements of the organization's business strategy [13]. In a complex environment it has become significantly difficult to define and attain goals, due to a constant change in requirements and expectations from the part of stakeholders as well as to meet the deadlines [14].

As the aim of the research is to determine and show the most common challenges in managing projects in the Republic of Serbia and to highlight the effect of the company size on different challenges, the following hypotheses are defined:

Hypothesis 1: The biggest challenges for project managers in Serbia are poorly defined goals, changes in scope and unrealistic deadlines.
Hypothesis 2: There is a statistically significant correlation between the size of the company and the completion of the project in a defined timeframe.

The bigger the project and the company, the greater the number of people, amount of resources, length and activities involved. In Serbia, large projects are generally executed by large companies.

Large companies have more large projects in their portfolio and reports show that large projects have five times less chance of being completed successfully. Large companies have more obstacles in successfully completing projects, some of which may include timeframe, unplanned risks, and restrains from the part of legal system, legislation and work with state institutions. Hypotheses 2, 3 and 4 are going to be tested to prove that this also applies to Serbian large companies.

Hypothesis 3: There is a statistically significant correlation between the size of the company and the challenges related to unplanned risks.

The avoidance of the risk analysis in some companies was the cause of a lot of project failures. According to Cordel "it's not rare that more than 50\% of companies' big project fails", because they don't take into account all the potential risks and especially human risks which are the most numerous and the most present. Secondly, companies have to consider that risk can occur directly during the project launch $[15,16]$.

Hypothesis 4: There is a statistically significant correlation between the size of the company and challenges related to the legal system, legislation and work with state institutions.

As building blocks of development, projects must be identified and defined within a larger development context. National plans must be more closely linked to proposals for action and define specific policy, program, and project activities required to facilitate plan implementation. Creation of project identification units, distribution of identification responsibility to regional and provincial governments, creation of sectoral programming offices within the operating ministries, and establishment of project preparation teams need to be supported by the legal system, legislation and practice in state institutions [17].

\section{METHODOLOGY}

In the study presented a three-phase approach was used: we first identified the challenges via a Systematic Literature Review (SLR) in order to understand the subject matter and to appreciate the contributions from other researchers, then the identified challenges were included in a questionnaire-based survey and sent to project management professionals. The last phase involved statistical analysis, descriptive and analytical, followed by conclusions and recommendations.

Data collection for the research part of this paper was done through a formulated research questionnaire that will show the most common challenges in project management in the Republic of Serbia, making a correlation between the challenges and size of a 
company, proving or discarding hypotheses. The questionnaire has 18 questions divided into two parts and organized in a way that are applicable to any company using project management as a tool for achieving business goals.

\section{A. Survey questionnaire}

Survey research was used as a common method of collecting information about a population of interest, which in this case were project managers in Serbia. As there are many different types of surveys, several ways to administer them and many methods of sampling, for the purpose of this study "Questionnaire" was chosen as the most convenient to gather the information. Sampling was done by searching the IPMA Serbia database of registered project managers in Serbia.

\section{B. Questionnaire design}

In the questionnaire designed for this study, only closed-ended questions were used, both in the first and in the second part of the questionnaire.

The first part, consisting of 4 questions, was used to collect demographic data, such as company size, ownership, length of presence on the market and sector, being industrial or service. Demographic data collected are shown in tables from 1 to 5 in this paper.

The second part consisting of 14 questions related to the research objective, used project management challenges most often cited in the literature, in order to see those through the perspective of project managers in Serbia.

Likert scale was used to make claims, ranging from 1 to 6 with the possible answers "strongly disagree", "disagree", "partly disagree", "partly agree", "agree" and "strongly agree". For two questions "yes" or "no" were the options. This approach was used because of the ease of counting the frequency of each response.

There were no open-ended questions in the questionnaire.

\section{Survey participants}

To conduct the Survey, 83 project management professionals were invited to participate, and 66 of them responded, which is the response rate of $79.52 \%$.

Professionals were selected from micro, small, medium-sized and large companies predominantly from service sector. Age and gender were not relevant.
All participants were selected on the basis that they have 10 or more years of experience in project management. The reference criteria for selecting the group of participants, besides experience was that companies are located in Serbia and operate locally or internationally. The questionnaire did not assume the differentiation between companies affiliation. Regarding the distribution by geographical origin, $74 \%$ of companies are located in central Serbia.

\section{Statistical methods}

Statistical methods for investigating mass phenomena can be divided into two basic groups. One group includes methods of collecting, arranging and displaying, and modelling of parameters, and this falls within the domain of descriptive statistics. Variables such as size, type, type of company activity, etc. are categorical (nominal) variables and are usually calculated for the values of average, median, modus and standard deviation. Significant statistical parameters for these variables are given in the descriptive statistics table where the data on the total number of respondents and percentage by categories projects.

The second group consists of methods of statistical analysis, whose basic task is an explanation of variability using classification, correlation and other statistical indicators, as well as statistical conclusion based on the sample. These methods deal with analytical statistics, which, however, can not be severely distinguished from descriptive statistics.

By examining a certain phenomenon on all units of the statistical set, we obtain a lot of statistical data. The presence of a multitude of numerical data, regardless of how they are arranged, are causing difficulties in obtaining a unique, clear, concise and comprehensive idea of the phenomenon we are observing. Therefore, we are trying to replace the data series with one or more number of numerical characteristics that would provide as much information as possible about the gathering and to represent the set.

\section{ANALYSIS OF DATA}

\section{A. Demographic data}

For the purpose of a more sensible and noticeable observation of the obtained results of the descriptive analysis of demographic data, are shown in tables from 1 to 5 .

TABLE I. COMPANY SIZE

\begin{tabular}{|c|c|c|c|c|}
\hline & & Frequency & Per cent & Cumulative Per cent \\
\hline \multirow{5}{*}{ 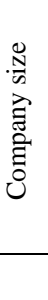 } & Micro up to 10 & 9 & 13.6 & 13.6 \\
\hline & Small from 10 to 50 & 12 & 18.2 & 31.8 \\
\hline & Medium from 51 to 250 & 12 & 18.2 & 50.0 \\
\hline & Large more than 250 & 33 & 50.0 & 100.0 \\
\hline & Total & 66 & 100.0 & \\
\hline
\end{tabular}


TABLE II. COMPany Size With Two Distinct Groups

\begin{tabular}{|c|c|c|c|c|}
\hline & & Frequency & Per cent & Cumulative Per cent \\
\hline \multirow{3}{*}{ 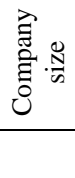 } & Company 1 & 33 & 50.0 & 50.0 \\
\hline & Company 2 & 33 & 50.0 & 100.0 \\
\hline & Total & 66 & 100.0 & \\
\hline
\end{tabular}

From the above-shown Table 1 and Table 2, we can notice that the survey was conducted on a sample of 66 surveyed companies in the Republic of Serbia, half of which are companies with more than 250 employees, and the other half are employed in smaller companies. In order to compare companies, and due to an uneven number of respondents in companies of all size categories, micro, small and medium enterprises were grouped into a new category "Company 1", while large companies remained in the same category, named "Company 2". The least number of respondents are employed in micro-size companies (up to 10 employees) $\mathrm{N}=9(13.6 \%)$, while the same percentage of employees is from small and medium-sized enterprises is $18.2 \%$ (Table 1 and Table 2).
More than half of the respondents work in domestic companies $\mathrm{N}=39(59.1 \%)$, much less owned by foreign companies $\mathrm{N}=15$ (22.7\%), and only $13.6 \%$ of respondents work in mixed-ownership companies (Table 3).

The largest number of companies $\mathrm{N} 45(68.2 \%)$ are present on the market for more than 20 years, N 15 $(22.7 \%)$ are present less than 10 years and only $\mathrm{N} 6$ $(9.1 \%)$ between 10 and 20 years (Table 4$)$.

The sample is mostly made up of employees in the service sector $\mathrm{N}=60(90.9 \%)$, while only $\mathrm{N}=6(9.1 \%)$ (Table 5) is employed in industrial sector.

TABLE III. OWNERSHIP

\begin{tabular}{ccccc}
\hline & & Frequency & Per cent & Cumulative Percent \\
\hline Valid & Foreign & 15 & 22.7 & 23.8 \\
& Domestic & 39 & 59.1 & 85.7 \\
& Mixed & 9 & 13.6 & 100.0 \\
& Total & 63 & 95.5 & \\
Missing & System & 3 & 4.5 & \\
\hline Total & & 66 & 100.0 & \\
\hline
\end{tabular}

TABLE IV. PRESENCE ON THE MARKET

\begin{tabular}{cccc}
\hline & Frequency & Per cent & Cumulative Percent \\
\hline Less than 10 years & 15 & 22.7 & 22.7 \\
From 10 to 20 years & 6 & 9.1 & 31.8 \\
More than 20 years & 45 & 68.2 & 100.0 \\
\hline Total & 66 & 100.0 & \\
\hline
\end{tabular}

TABLE V. COMPANY SECTOR

\begin{tabular}{cccc}
\hline & Frequency & Per cent & Cumulative Percent \\
\hline Industrial & 6 & 9.1 & 9.1 \\
Service & 60 & 90.9 & 100.0 \\
\hline Total & 66 & 100.0 & \\
\hline
\end{tabular}




\section{B. Internal Consistency and Validity}

A Cronbach's alpha coefficient of reliability was calculated because the Likert scale was used in a questionnaire [18].

Cronbach's $\alpha$ as a common test for internal consistency [19] for this study is $\alpha=0.80$, which is considered good reliability of internal consistency.

Face validity was checked with the help of respondents who agreed that all items correspond to the presumed object of measurement, or the assumed challenges in the project management.

\section{Interpretation of results}

In Table 6 below descriptive statistics from SPSS are shown, and results discussed.

1) Interpretation of descriptive statistics results

Respondents answered a total of 14 questions, 2 of which as "yes" or "no" and 12 constructed as claims, with Likert scale rating from 1 to 6 , from strongly disagree to strongly agree. First, frequency and descriptive statistical analysis was conducted where the

TABLE VI. DESCRIPTIVE STATISTICS OF THE RESUlts

\begin{tabular}{|c|c|c|c|c|c|c|}
\hline No & Questions in the survey & $\mathrm{N}$ & Min. & Max. & Mean & St. Dev. \\
\hline 1. & $\begin{array}{l}\text { Completion of the project within a defined timeframe is } \\
\text { often the biggest challenge to you as a team member or project } \\
\text { manager. }\end{array}$ & 66 & 2 & 6 & 4.59 & 1.240 \\
\hline 2. & $\begin{array}{l}\text { Poorly defined goals often represent a real obstacle to the } \\
\text { successful implementation of the project. }\end{array}$ & 66 & 1 & 6 & 4.77 & 1.093 \\
\hline 3. & $\begin{array}{l}\text { In your previous experience, unrealistic deadlines have led } \\
\text { to an increase in tension in project teams and a decrease in the } \\
\text { quality level of individual contributions of team members. }\end{array}$ & 66 & 2 & 6 & 5.09 & 1.133 \\
\hline 4. & $\begin{array}{l}\text { Frequent changes in the scope of the project for which } \\
\text { requests came from different stakeholders made the work of the } \\
\text { project team more difficult, and the implementation of the } \\
\text { project was difficult. }\end{array}$ & 66 & 4 & 6 & 5.00 & 679 \\
\hline 5. & Do you use project management software? & 66 & 1 & 2 & 1.77 & .422 \\
\hline 6. & $\begin{array}{l}\text { Answer this question if the answer to the previous question } \\
\text { is "yes": The use of software in project management contributes } \\
\text { to the efficiency of your project team. }\end{array}$ & 51 & 4 & 6 & 4.88 & .683 \\
\hline 7. & $\begin{array}{l}\text { Your project team is, in most cases, geographically located } \\
\text { in one place. }\end{array}$ & 66 & 1 & 2 & 1.50 & .504 \\
\hline 8. & $\begin{array}{l}\text { Answer this question if the answer to the previous question } \\
\text { is "no": The geographical dislocation of team members (time } \\
\text { zones, language barriers) negatively impact their results. }\end{array}$ & 36 & 2 & 5 & 4.08 & .874 \\
\hline 9. & $\begin{array}{l}\text { Unplanned risks related to costs, scheduling and } \\
\text { performance that badly influenced project implementation often } \\
\text { emerge. }\end{array}$ & 66 & 2 & 5 & 4.14 & 1.021 \\
\hline 10 . & $\begin{array}{l}\text { Simultaneous engagement of team members on several } \\
\text { projects had a negative impact on the results of the project. }\end{array}$ & 66 & 2 & 6 & 4.55 & 1.040 \\
\hline 11. & $\begin{array}{l}\text { Lack of necessary competencies in the project team led to } \\
\text { problems arising at all stages of project management. }\end{array}$ & 66 & 2 & 6 & 4.45 & 1.084 \\
\hline 12. & $\begin{array}{l}\text { Representatives of top management and investors as key } \\
\text { stakeholders often do not show sufficient interest in the project, } \\
\text { which slows down the decision making and implementation of } \\
\text { activities. }\end{array}$ & 66 & 1 & 6 & 4.18 & 1.446 \\
\hline 13. & $\begin{array}{l}\text { The legal system, legislation and work with state institutions } \\
\text { in relevant areas often represent a limiting factor for the } \\
\text { execution of the project. }\end{array}$ & 66 & 2 & 6 & 4.55 & 1.084 \\
\hline 14. & $\begin{array}{l}\text { Different aspects of political and economic instability in } \\
\text { Serbia have had a negative impact on the successful completion } \\
\text { of the projects in which you participated. }\end{array}$ & 66 & 2 & 6 & 4.05 & 1.233 \\
\hline
\end{tabular}


the arithmetic mean of the response and dispersion of responses were evaluated, followed by a crosstabulation analysis in which responses were correlated to the assertions from the questionnaire with the variable "company size".

The following conclusions can be drawn from this research according to data in Table 6 .

- Respondents agree on average that the completion of the project within a defined deadline is often the biggest problem for the member of the project team or for the manager $($ Mean $=4.59)$.

- Respondents agree on average that defined goals are very often a real obstacle to the successful execution of the project $($ Mean $=$ 4.77).

- Compared with other claims, the respondents generally agree that in the previous experience, unrealistically defined deadlines led to a rise of tensions in project teams and to a decrease in the quality of individual contributions of team members $($ Mean $=5.09)$.

- Respondents' answers are also very homogeneous in agreement with the assertion that frequent changes in the scope of the project, for which requests came from different stakeholders, made it difficult for the project team to work on project execution (5.00).

- Most respondents agree with the assertion that project management software contributes to project team efficiency $($ Mean $=4.88)$.

- It can be said that the geographical dislocation of team members (time zones, language barriers) has a partial negative impact on their results $($ Mean $=4.08)$.

- Respondents partially agree with the assertion that the occurrence of unplanned risks related to costs, scheduling and performance has often poorly influenced project implementation $($ Mean $=4.14)$.

- Respondents strongly agree that the simultaneous engagement of team members on several projects negatively reflected on the results of the project $($ Mean $=4.55)$.

- Respondents, for the most part, agree that the lack of necessary competencies within the project team led to problems arising at all stages of project management $($ Mean $=4.45)$.

- Respondents partially agree with the claim that representatives of top management and investors as key stakeholders often do not show sufficient interest in the project, which slows down decision making and implementation of activities $($ Mean $=4.18)$.

- Respondents agree that the legal system and regulations in relevant areas often represent a limiting factor for the project implementation $($ Mean $=4.55)$.

- Respondents partially agree that different aspects of political and economic instability in Serbia have had a negative impact on the successful completion of the projects in which respondents participated $($ Mean $=4.05)$.

- Respondents partially agree that different aspects of political and economic instability in Serbia have had a negative impact on the successful completion of the projects in which respondents participated $($ Mean $=4.05)$.

\section{2) Hypothesis 1 proof}

Proof for hypothesis 1 is based on descriptive statistics results shown in Table 7 .

From the results in Table 7, we can see that for the claim that the biggest challenges for project managers in Serbia are poorly defined goals, changes in scope and unrealistic deadlines, participants in the study, to a large extent (on average over $45 \%$ ), responded to agree with claims, or completely agree with the proposed claims (on average over 30\%). The least number of respondents (on average over 4\%), completely disagree or disagree with the claims.

With the assertion that poorly defined goals often represent a real obstacle to the successful implementation of the project, $45 \%$ of respondents agree, that is, $22.7 \%$ of respondents fully agree, while only $4.5 \%$ completely disagree with the above statement.

With the assertion that in the previous experience of the respondents unrealistic deadlines led to a rise in tension in project teams and a decrease in the level of quality of individual contributions of team members $45.5 \%$ of respondents fully agree, that is, $36.4 \%$ of respondents agree and only $4.5 \%$ of respondents disagree with this assertion

With the assertion that frequent changes in the scope of the project for which the requests came from different stakeholders hampered the work of the project team and project execution $54.5 \%$, that is, $22.7 \%$ of respondents fully agreed or partially agreed.

Hypothesis 1: The biggest challenges for project managers in Serbia are poorly defined goals, changes in scope and unrealistic deadlines is proved according to the descriptive statistical results because a high percentage (over 75\%) of respondents fully agree with or agree with stated claims. 
TABLE VII.

DesCriptive Statistics - Biggest Challenges for ProjeCt MANAgers

\begin{tabular}{|c|c|c|c|c|c|c|c|c|c|c|c|c|}
\hline \multirow[t]{2}{*}{ Claims/assertions } & \multicolumn{2}{|c|}{$\begin{array}{l}\text { Strongly } \\
\text { disagree }\end{array}$} & \multicolumn{2}{|c|}{ Disagree } & \multicolumn{2}{|c|}{$\begin{array}{c}\text { Partly } \\
\text { disagree }\end{array}$} & \multicolumn{2}{|c|}{$\begin{array}{l}\text { Partly } \\
\text { agree }\end{array}$} & \multicolumn{2}{|c|}{ Agree } & \multicolumn{2}{|c|}{$\begin{array}{c}\text { Strongly } \\
\text { agree }\end{array}$} \\
\hline & $\mathrm{F}$ & $\%$ & $\mathrm{~F}$ & $\%$ & $\mathrm{~F}$ & $\%$ & $\mathrm{~F}$ & $\%$ & $\mathrm{~F}$ & $\%$ & $\mathrm{~F}$ & $\%$ \\
\hline $\begin{array}{l}\quad \text { Poorly defined goals often } \\
\text { represent a real obstacle to the } \\
\text { successful implementation of the } \\
\text { project. }\end{array}$ & 3 & 4.5 & & & 18 & 27.3 & & & 30 & 45.5 & 15 & 22.7 \\
\hline $\begin{array}{l}\text { In your previous experience, } \\
\text { unrealistic deadlines have led to an } \\
\text { increase in tension in project teams } \\
\text { and a decrease in the quality level of } \\
\text { individual contributions of team } \\
\text { members. }\end{array}$ & & & 3 & 4.5 & 6 & 9.1 & 3 & 4.5 & 24 & 36.4 & 30 & 45.5 \\
\hline $\begin{array}{l}\text { Frequent changes in the scope of } \\
\text { the project for which requests came } \\
\text { from different stakeholders made the } \\
\text { work of the project team more } \\
\text { difficult, and the implementation of } \\
\text { the project was difficult. }\end{array}$ & & & & & & & 15 & 22.7 & 36 & 54.5 & 15 & 22.7 \\
\hline MEAN & 3 & 4.5 & 3 & 4.5 & 12 & 18.2 & 9 & 13.6 & 30 & 45.5 & 20 & 30.3 \\
\hline
\end{tabular}

\section{3) Hypothesis 2 proof}

For the proof of hypothesis 2, both descriptive and analytical statistics were used. Cross-tabulation of results was done for questions 1,9 and 13 , which are directly related to hypothesis 2,3 and 4 .

Results for the claim that completion of the project within a defined timeframe is often the biggest challenge for a team member or project are shown in Figure 1.

The conclusion is that completion of the project within a defined timeframe is a bigger challenge for large than for small, micro and medium-sized companies.

In addition to descriptive statistics, the Chi-squared test of independence was applied in analyzing the hypotheses in this paper. The statistics literature often discusses two types of statistical techniques: parametric and non-parametric. The Chi-squared uncertainty test belongs to non-parametric techniques, and these techniques are ideal for data measured at nominal (categorical) or ordinal (whose ranges can be ranked) scales. They are also useful when there are very small samples or when the data does not meet the strict assumptions of the parametric techniques.

The Chi-squared test explores the relationship between two categorical variables. Each of them can have two or more categories. The test compares the frequency or proportion of cases observed in each of the categories, with values that would be expected to have nothing to do between the two measured variables. It is based on a cross-table, where the categories of one variable are crossed with the categories of the other; each cell of the cross-table containing one combination of the categories of the observed variables.

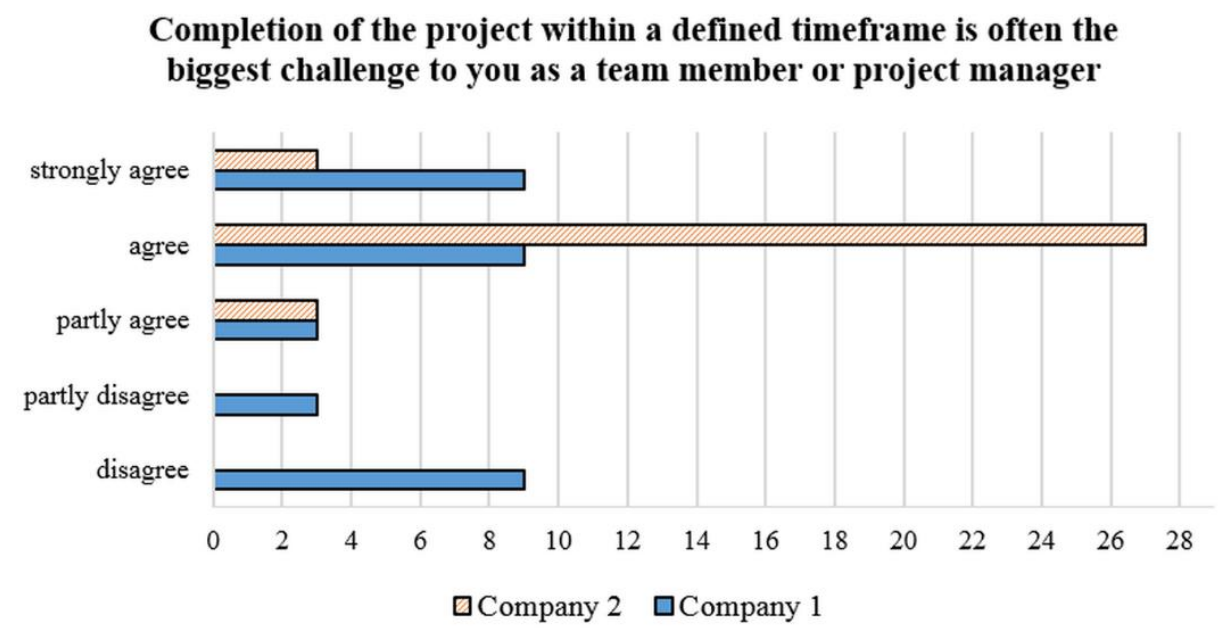

Fig. 1. Completion of project answers in groups Company 1 and Company 2 
In Table 8 Chi-squared independence test, there are statistics, frequency, percentage and statistical significance of the relationship / size difference of the company and the idea that the completion of the project within the defined timeframe is often the biggest challenge for a team member or project manager.

In order to check whether there is a statistical relationship between the size of the company and the idea that the completion of the project within the defined timeframe is often the biggest challenge for a team member or project manager, we observe the results given in the column showing the reliability coefficient (p), more precisely, statistical significance (at significance level 0.05)

The result of the Chi-squared test indicates that there is a statistically correlated relationship between the size of the company and the view that the completion of the project within the defined timeframe is often the biggest challenge for a team member or project manager, Sig. $=0.000<0.05$.

Hypothesis 2: There is a statistically significant correlation between the size of the company, and the completion of project in a defined timeframe is proved based on descriptive cross-tabulation and analytical Chi-squared test results.

\section{4) Hypothesis 3 proof}

For the proof of Hypothesis 3, the same approach was used for the proof of Hypothesis 2, descriptive and analytical statistics results.

In Figure 6 results of descriptive statistics crosstabulation are shown, from which a conclusion is drawn that project managers from large companies face unplanned risks related to costs, time schedule and performance, that had bad influence on project completion, more frequently than those in micro, small and medium-size.

In Table 9 results of the Chi-squared test are shown.

The results of the Chi-squared test indicate that there is a statistically correlated relationship between the size of the company and the notion that it is often the occurrence of unplanned risks related to costs, scheduling and performance that have poorly influenced project implementation, Sig. $=0.000<0.05$.

TABLE VIII. ChI-SQUARED INDEPENDENCE TEST ON QUESTION 1

\begin{tabular}{|c|c|c|c|c|c|c|c|c|}
\hline \multicolumn{9}{|c|}{ Completion of the project within a defined timeframe is often the biggest challenge to you as a team member or project manager } \\
\hline & & Disagree & Partly disagree & Partly agree & Agree & Strongly agree & Total & $\begin{array}{l}\text { Sig. } \\
(p)\end{array}$ \\
\hline \multirow{4}{*}{$\begin{array}{l}\stackrel{\tilde{N}}{\omega} \\
\text { त्ञ } \\
\text { है } \\
0\end{array}$} & \multirow{2}{*}{ Company 1} & 9 & 3 & 3 & 9 & 9 & 33 & \multirow{4}{*}{0.000} \\
\hline & & $27.3 \%$ & $9.1 \%$ & $9.1 \%$ & $27.3 \%$ & $27.3 \%$ & $100.0 \%$ & \\
\hline & \multirow[b]{2}{*}{ Company 2} & 0 & 0 & 3 & 27 & 3 & 33 & \\
\hline & & $0.0 \%$ & $0.0 \%$ & $9.1 \%$ & $81.8 \%$ & $9.1 \%$ & $100.0 \%$ & \\
\hline \multirow{2}{*}{\multicolumn{2}{|c|}{ Total }} & 9 & 3 & 6 & 36 & 12 & 66 & \\
\hline & & $13.6 \%$ & $4.5 \%$ & $9.1 \%$ & $54.5 \%$ & $18.2 \%$ & $100.0 \%$ & \\
\hline
\end{tabular}

\section{Unplanned risks related to costs, scheduling and performance that badly influenced project implementation often emerge}

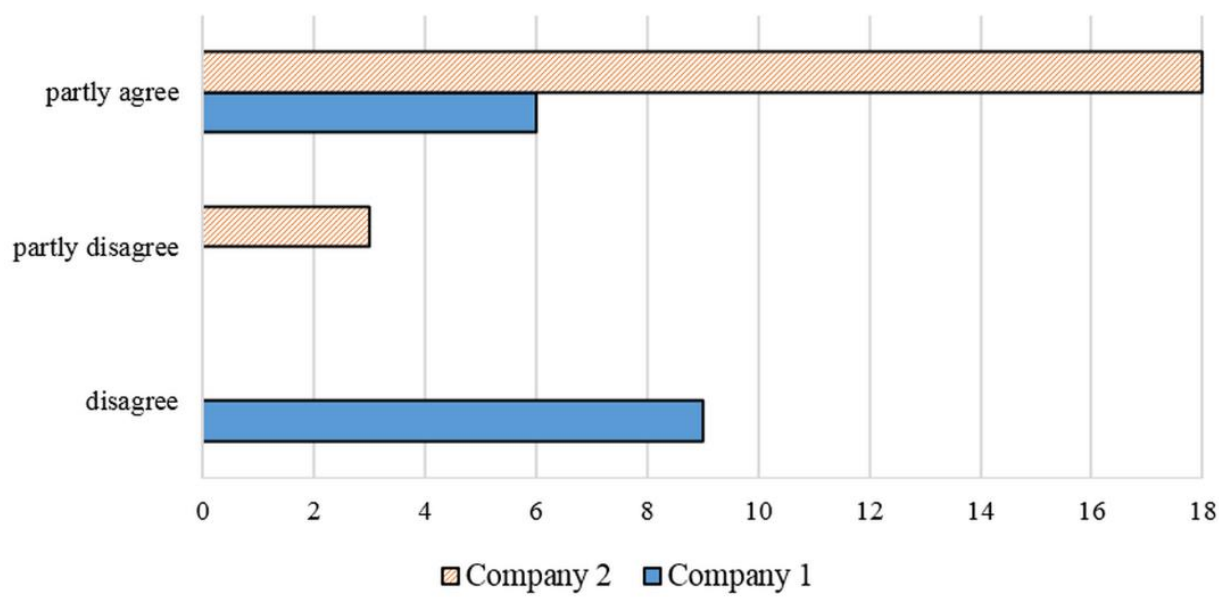

Fig. 2. Unplanned risks - answers in groups Company 1 and Company 2 


\begin{tabular}{|c|c|c|c|c|c|c|c|}
\hline & & Disagree & Partly disagree & Partly agree & Agree & Total & $\begin{array}{l}\text { Sig. } \\
(p)\end{array}$ \\
\hline \multirow{4}{*}{ 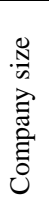 } & \multirow{2}{*}{ Company 1} & 9 & 0 & 6 & 18 & 33 & \multirow{4}{*}{0.000} \\
\hline & & $27.3 \%$ & $0.0 \%$ & $18.2 \%$ & $54.5 \%$ & $100.0 \%$ & \\
\hline & \multirow[b]{2}{*}{ Company 2} & 0 & 3 & 18 & 12 & 33 & \\
\hline & & $0.0 \%$ & $9.1 \%$ & $54.5 \%$ & $36.4 \%$ & $100.0 \%$ & \\
\hline & \multirow{2}{*}{ Total } & 9 & 3 & 3 & 30 & 66 & \\
\hline & & $13.6 \%$ & $4.5 \%$ & $4.5 \%$ & $45.5 \%$ & $100.0 \%$ & \\
\hline
\end{tabular}

Hypothesis 3: There is a statistically significant correlation between the size of the company and the challenges related to unplanned risks is proved based on descriptive cross-tabulation and analytical Chi-squared test results.

\section{5) Hypothesis 4 proof}

For the proof of Hypothesis 4, the same approach was used for the proof of Hypothesis 2 and 3, descriptive and analytical statistics results.

In Figure 3 results of descriptive statistics, crosstabulation are shown, with the conclusion that the legal system, regulations and work with state institutions in relevant areas often represent a limiting factor for the execution of the project in greater extent in large companies than in micro, small and medium-size.
In Table 10 results of the Chi-squared test are shown.

The result of the Chi-squared test indicates that there is a statistically correlated relationship between the size of the company and the view that the legal system, legislation and work with state institutions in relevant areas often represent a limiting factor for the execution of the project, Sig. $=0.028<0.05$.

Hypothesis 4: There is a statistically significant correlation between the size of the company and challenges related to the legal system, legislation and work with state institutions is proved based on descriptive cross-tabulation and analytical Chisquared test results.

\section{Legal system, legislation and work with state institutions in relevant areas often represent a limiting factor for the execution of the project}

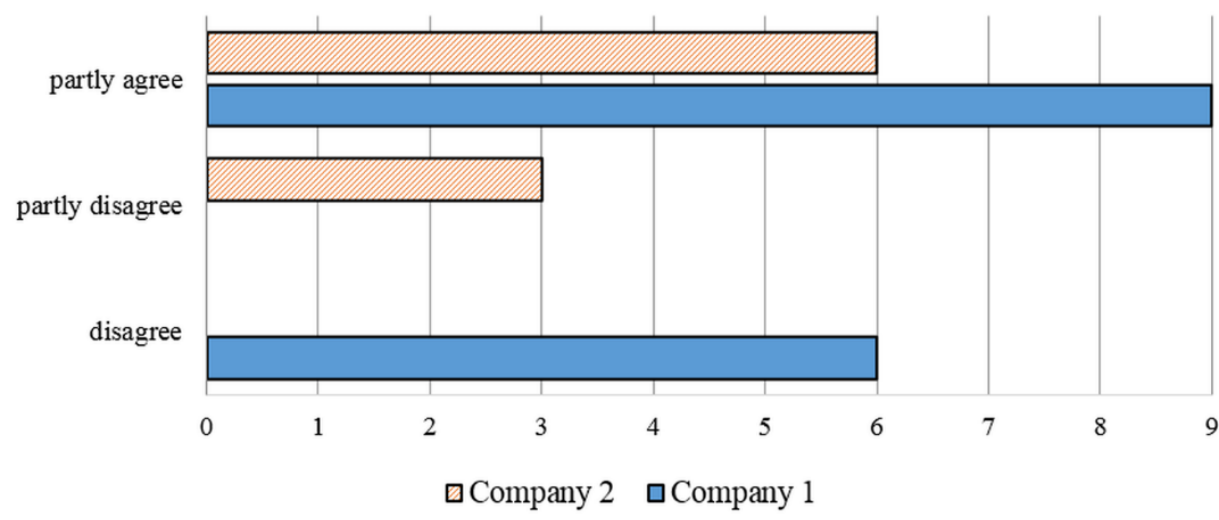

Fig. 3. Regulations - answers in groups Company 1 and Company 2 
TABLE X. ChI-SQUARED INDEPENDENCE TEST ON QUESTION 13

The legal system, legislation and work with state institutions in relevant areas often represent a limiting factor for the execution of the project

\begin{tabular}{|c|c|c|c|c|c|c|c|c|}
\hline & & Disagree & $\begin{array}{c}\text { Partly } \\
\text { disagree }\end{array}$ & Partly agree & Agree & Strongly agree & Total & $\begin{array}{l}\text { Sig. } \\
(p)\end{array}$ \\
\hline \multirow{4}{*}{ 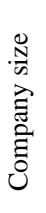 } & \multirow{2}{*}{ Company 1} & 6 & 0 & 9 & 15 & 3 & 33 & \multirow{4}{*}{0.028} \\
\hline & & $18.2 \%$ & $0.0 \%$ & $27.3 \%$ & $45.5 \%$ & $9.1 \%$ & $100.0 \%$ & \\
\hline & \multirow[b]{2}{*}{ Company 2} & 0 & 3 & 6 & 18 & 6 & 33 & \\
\hline & & $0.0 \%$ & $9.1 \%$ & $18.2 \%$ & $54.5 \%$ & $18.2 \%$ & $100.0 \%$ & \\
\hline & \multirow[b]{2}{*}{ Total } & 6 & 3 & 15 & 33 & 9 & 66 & \\
\hline & & $9.1 \%$ & $4.5 \%$ & $22.7 \%$ & $50.0 \%$ & $13.6 \%$ & $100.0 \%$ & \\
\hline
\end{tabular}

\section{Discussion}

Successful implementation of project management requires a holistic approach [20]. It requires commitment at a high level within the organization which should provide a complete infrastructure for projects to achieve specific business objectives.

According to the literature review, project managers face similar challenges worldwide. This does not depend on the country, economy, political stability or other factors. It depends mostly on competencies of individuals. The aim of the research conducted and shown in this paper was to test if major challenges are the same for project managers in Serbia, which was done by testing Hypothesis 1 . The aim was, as well, to test the significance of correlation between the company size and significance of correlation between the company size and challenges in timeframe, unplanned risks and restrains from the part of legal system, legislation and work with state institutions, which was done by testing Hypothesis 2, 3 and 4.

All four hypotheses were proved and accepted. The following conclusions were drawn:

1. The biggest challenges for project managers in Serbia are poorly defined goals, changes in scope and unrealistic deadlines.

2. There is a statistically significant correlation between the size of the company and the completion of project in a defined timeframe, such that this is a bigger challenge for large than for micro, small and medium-sized companies.

3. There is a statistically significant correlation between the size of the company and challenges related to unplanned risks, such that large companies face unplanned risks related to costs, time schedule and performance, that had bad influence on project completion, more frequently than those in micro, small and medium-size.

4. There is a statistically significant correlation between the size of the company and challenges related to the legal system, legislation and work with state institutions, such that this is present in greater extent in large companies than in micro, small and medium-size ones.

Results from the research presented in this paper are to provide project managers and decision-makers clearer understanding of scope of challenges in project management practice in Serbia, pointing also to the correlation of the company size and specific challenges faced and at the same time broadening the research aspects, considering the lack of such research in the literature. The study opens the possibility for future research in terms of searching through industrial sector as well, testing different other challenges and comparing to different demographic data.

\section{REFERENCES}

[1] G.V. Patil, "Project management challenges", Journal of multidisciplinary engineering science and technology, ISSN: 2458-9403, vol. 3, issue 11, pp. 6019 - 6024, November 2016.

[2] P. Bauer, "Introducing a capacity management maturity model", white paper, Team Quest Corporation EMEA.

[3] M. L. Pettus, Y. Y. Kor, J. T. Mahoney "A theory of change in turbulent environments: the sequencing of dynamic capabilities following industry deregulation", International journal of strategic change management 1(07-0100)DOI: 10.1504/IJSCM.2009.024509, January 2007

[4] E. G. Carayannis, Y. H. Kwak, F. T. Anbari, The story of managing projects (chapter 2, Brief history of project management), Quorum Books, 2003.

[5] R. Wagner, "Projects and project management in Serbia", Serbian Project Management Journal, vol. 6, issue 2, Publisher: Serbian Project Management Association, December 2016.

[6] World Bank national accounts data and OECD National Accounts data files, https://data.worldbank.org/indicator/ ny.gdp.pcap.cd, retrieved on March 14th, 2019.

[7] P. Petrovic, D. Vesic, "Impact of global economic crisis on Serbia's economic development", International problems, a journal published by the Institute of international politics and economics, vol. LXVII Belgrade no. 1/2015, pp. 106-127, 2015

[8] D. S. L. Jarvis, "The OECD and the reconfiguration of the state in emerging economies: manufacturing "regulatory capacity" ", Development and Change, vol. 48, issue 6, pp. 1386-1416, November 2017.

[9] A. Adams, "Project management for developing countries: 
back to basics", Dama International Journal of Researchers, vol. 2, issue 4, pp.05-09, April 2017.

[10] C. W. Ibbs, C. K. Wong, Y. H. Kwank, "Project Change Management System", Journal of Management in Engineering vol. 17, issue 3, DOI: 10.1061/(ASCE)0742-597X(2001) 17:3(159), July 2001

[11] F. Meléndez de la Cruz, V. Anyosa Soca, "Effective management of fixed deadline projects", Paper presented at PMI $^{\circledR}$ Global Congress 2008 - North America, Denver, CO. Newtown Square, PA: Project Management Institute

[12] A. Badewi, "The impact of project management (PM) and benefits management (BM) practices on project success: Towards developing a project benefits governance framework", International Journal of Project Management, vol. 34, issue 4, pp. 761-778, May 2016.

[13] E. G. Too, P. Weaver, "The management of project management: A conceptual framework for project governance", International Journal of Project Management, vol. 32, issue 8, pp. 1382 - 1394, November 2014.

[14] K. Remington, R. Zolin, R. Turner, "A model of project complexity: distinguishing dimensions of complexity from severity," Proceedings of the 9th International Research
Network of Project Management Conference, Berlin, IRNOP, October 2009.

[15] F. Cordel, "Échecs de grands projets d'entreprise : brisons le tabou", May 2013, available at: http://lecercle.lesechos.fr/ entreprises-marches/management/autres/221171697/echecsgrandsprojets-dentreprise-brisons-tabou, retrieved on April $15^{\text {th }}, 2019$.

[16] D. Toljaga - Nikolić, M. Todorović, D. Bjelica, “Application of the FMEA technique in a project risk analysis", European Project Management Journal, vol. 8, issue 2, December 2018.

[17] J. W. Cusworth, T. R. Franks, Managing projects in developing countries, Routledge, e-book 2013.

[18] I. Serbetar, I. Sedlar, "Assessing reliability of a multidimensional scale by coefficient alpha". Revija za Elementarno Izobrazevanje, vol. 9, numbers 1-2, pp.189-195, 2016.

[19] N. M. Webb, R. J. Shavelson, E.H. Haertel, "Reliability coefficients and generalizaibility theory." Handbook of Statistics, vol. 26, p. 2. ISSN 0169-7161, 2006.

[20] D. Chronéer, F. Backlund, "A holistic view on learning in project - based organizations", Project Managementt Journal, vol. 46, no. 3, pp. 61-74, DOI:10.1002/pmj.21503, June/July 2015 